\title{
Effect of Cylinder Size on the Modulus of Elasticity and Compressive Strength of Concrete from Static and Dynamic Tests
}

\author{
Byung Jae Lee, ${ }^{1}$ Seong-Hoon Kee, ${ }^{2}$ Taekeun $\mathrm{Oh}^{3}$ and Yun-Yong Kim ${ }^{4}$ \\ ${ }^{1}$ R\&D Center, JNTINC Co. Ltd., 9 Hyundaikia-ro 830 beon-Gil, Bibong-Myeon, Hwaseong, Gyeonggi-do 18284, Republic of Korea \\ ${ }^{2}$ Department of Architectural Engineering, Dong-A University, 37 Nakdong-Daero 550 beon-Gil, Saha-gu, \\ Busan 49315, Republic of Korea \\ ${ }^{3}$ Department of Safety Engineering, Incheon National University, 119 Academy-ro, Yeonsu-gu, Incheon 22012, Republic of Korea \\ ${ }^{4}$ Department of Civil Engineering, Chungnam National University, 99 Daehak-ro, Yuseong-gu, Daejeon 34134, Republic of Korea
}

Correspondence should be addressed to Seong-Hoon Kee; shkee@dau.ac.kr

Received 1 June 2015; Revised 23 August 2015; Accepted 2 September 2015

Academic Editor: Santiago Garcia-Granda

Copyright (C) 2015 Byung Jae Lee et al. This is an open access article distributed under the Creative Commons Attribution License, which permits unrestricted use, distribution, and reproduction in any medium, provided the original work is properly cited.

\begin{abstract}
The primary objective of this study is to investigate the effects of cylinder size (150 by $300 \mathrm{~mm}$ and 100 by $200 \mathrm{~mm}$ ) on empirical equations that relate static elastic moduli and compressive strength and static and dynamic elastic moduli of concrete. For the purposes, two sets of one hundred and twenty concrete cylinders, 150 by $300 \mathrm{~mm}$ and 100 by $200 \mathrm{~mm}$, were prepared from three different mixtures with target compressive strengths of 30,35, and $40 \mathrm{MPa}$. Static and dynamic tests were performed at 4, 7, 14, and 28 days to evaluate compressive strength and static and dynamic moduli of cylinders. The effects of the two different cylinder sizes were investigated through experiments in this study and database collected from the literature. For normal strength concrete $(\leq 40 \mathrm{MPa})$, the two different cylinder sizes do not result in significant differences in test results including experimental variability, compressive strength, and static and dynamic elastic moduli. However, it was observed that the size effect became substantial in high strength concrete greater than $40 \mathrm{MPa}$. Therefore, special care is still needed to compare the static and dynamic properties of high strength concrete from the two different cylinder sizes.
\end{abstract}

\section{Introduction}

The elastic modulus of concrete $E_{c}$ is of great interest for design of new structures and condition assessment of existing structures. In structure design, there are requirements for serviceability of concrete structures such as maximum permissible deflections and allowable story drift for high-rise buildings in general building codes $[1,2] . E_{c}$ is a fundamental parameter for calculating the static and dynamic behavior of structural elements (e.g., deflection, side sway of tall buildings, and vibration of concrete elements). Furthermore, $E_{c}$ is a good indicator of degree of concrete deterioration: more degradation results in lower $E_{c}$. Therefore, $E_{c}$ is popularly used for condition assessment of concrete structures such as building components, pavements, and bridge decks [3].

Elastic modulus of concrete $E_{c}$ is directly measured by the static uniaxial compressive test in accordance with ASTM
C469 [4], which is called static elastic modulus. In practice, $E_{c}$ is generally determined from compressive strength based on design codes rather than on the direct measurement. ACI 318 committee [1] proposes an empirical equation that relates $E_{c}$ and $F_{c}$ :

$$
E_{\mathrm{ACI} 318}=0.043 w_{c}^{1.5} \sqrt{F_{c}}(\mathrm{MPa}),
$$

where $F_{c}$ is compressive strength of concrete in MPa and $w_{c}$ is a unit weight of concrete in $\mathrm{kg} / \mathrm{m}^{3}$ (for $1440 \leq w_{c} \leq$ $2560 \mathrm{~kg} / \mathrm{m}^{3}$ ) for a value of $F_{c}$ less than $38 \mathrm{MPa}$ [5]. Furthermore, ACI 363 committee [6] proposes a different equation for linking $E_{c}$ and $F_{c}$ for a value of $F_{c}$ between $21 \mathrm{MPa}$ and $83 \mathrm{Mpa}$

$$
E_{\mathrm{ACI} 363}=\left(\frac{w_{c}}{2300}\right)^{1.5}\left(3320 \sqrt{F_{c}}+6900\right)(\mathrm{MPa}) .
$$


For both normal strength and high strength concrete, the Comite-Euro-International du Béton and the Fédération Internationale de la Précontrainte (CEB-FIP) Model code and Eurocode 2 suggests an empirical equation relating $E_{c}$ and $F_{c}$ as follows:

$$
E_{\mathrm{CEB}-\mathrm{FIP}}=22000 \sqrt[3]{\frac{F_{c}}{10}}(\mathrm{MPa})
$$

However, it has been reported that the simple code equations may not always produce accurate $E_{c}$ compared to the value based on direct measurements $[7,8]$. In fact, there was no standard test method for determining $E_{c}$ when the equation adopted by ACI 318 [1] was developed: consequently, there was a substantial variation according to the definition of elastic modulus of concrete (i.e., initial, tangent, or secant modulus) [5]. Furthermore, the code equations (see (1)-(4)) do not take into account the critical parameters such as the type of coarse aggregates, mineral admixtures, and size of test specimens for compressive strength of concrete.

Elastic modulus of concrete $E_{c}$ can be determined by dynamic test methods such as ultrasonic pulse velocity and resonance frequency tests [9]. The resulting elastic modulus is commonly referred to as dynamic elastic modulus $E_{d}$, which is larger than static elastic modulus $E_{c}[10]$. There are several empirical equations that relate $E_{d}$ and $E_{c}$. Lydon and Balendran [11] proposed the following empirical relationship between $E_{d}$ and $E_{c}$ :

$$
E_{c}=0.83 E_{d}(\mathrm{GPa})
$$

The British testing standard BS8100 Part 2 [12] provides another empirical equation for $E_{c}$ as follows:

$$
E_{c}=1.25 E_{d}-19(\mathrm{GPa})
$$

It is noteworthy that this equation does not apply to concrete containing more than $500 \mathrm{~kg} / \mathrm{m}^{3}$ or to lightweight aggregate concrete [10]. A more general relationship was proposed by Popovics [13] for both lightweight and normal concrete, taking into account the effect of a unit weight of concrete:

$$
E_{c}=\frac{446.09 E_{d}^{1.4}}{w_{c}}(\mathrm{GPa}) .
$$

However, $E_{c}$ values for a given concrete predicted by different empirical equations do not agree with each other. In fact, it is known that the value of $E_{d}$ may vary significantly according to test methods and size and type of test specimens [7]. Therefore, it is difficult to select a correct equation that produces the least error for different dynamic tests and test specimens.

Requirements for the cylinder size of concrete are described in ASTM C192 [14] and ASTM C31 [15], which are adopted by general building code [1] and other ASTM standards for measuring compressive strength, static elastic modulus, and dynamic elastic moduli of concrete. Even though dimensions are not stipulated in a specification, test method, or practice, the concrete cylinder should have a diameter at least three times nominal maximum aggregate size and the heightto-diameter ratio of 2 . In practice, maximum aggregate size ranges between $12.5 \mathrm{~mm}$ and $25 \mathrm{~mm}$; therefore, a size of 100 by $200 \mathrm{~mm}$ cylinder is accepted by the standard tests method. The use of 100 by $200 \mathrm{~mm}$ cylinders has many advantages against using larger specimens (e.g., 150 by $300 \mathrm{~mm}$ cylinders) because it facilitates handling in practice and needs smaller space and reduces construction wastes. For dynamic elastic modulus, the frequency equations in ASTM C215 [16] are supposed to produce the same value of $E_{d}$ when test cylinder has the same diameter-to-height ratio without regard to cylinder sizes: however, different size of cylinder may produce inelastic effect and dispersion and consequently affect a value of $E_{d}$. For static tests, a number of researchers [17-24] have observed that the size of cylinders affects compressive strength and elastic modulus of concrete. In summary, the cylinder size may affect the accuracy of the empirical equations that relate compressive strength and static elastic modulus (see (1)-(3)) and dynamic and static elastic moduli (see (4)-(6)). However, it is difficult to quantitatively say the size effect due to scarcity of experimental data comparing various empirical equations for estimating static elastic modulus of concrete $E_{c}$ from compressive strength $F_{c}$ and dynamic elastic modulus of concrete $E_{d}$.

The primary objective of this study is to investigate the effect of cylinder size (100 by $200 \mathrm{~mm}$ and 150 by $300 \mathrm{~mm}$ ) on empirical equations that relate static and dynamic elastic moduli of concrete and static elastic modulus and compressive strength of concrete. For the purposes, a series of experimental studies was performed in the laboratory, which is described in Section 2. Main experimental variables in this study include the cylinder size (100 by $200 \mathrm{~mm}$ and 150 by $300 \mathrm{~mm}$ cylinders), concrete ages at the test (4, 7, 14, and 28 days), and compressive strength $(20,30$, and $40 \mathrm{MPa})$. The results (i.e., experimental variability, compressive strength, and static and dynamic elastic moduli) from various static and dynamic test methods are compared in Section 3. For a comparison, the experimental results in this study were compared with database collected from the literature.

\section{Experimental Program}

2.1. Preparation of Specimens. For experimental studies, two sets of one hundred and twenty concrete cylinders with different sizes (100 by $200 \mathrm{~mm}$ and 150 by $300 \mathrm{~mm}$ cylinders) were prepared in the laboratory. Concrete used in this study has the same mix proportions of Type I Portland cement, river sand, crushed granite with maximum size of $25 \mathrm{~mm}$, and mineral admixtures (fly ash and granulate-furnace slag), except for three different water-to-binder ratios (W/B), 0.3, 0.35, and 0.45 . Specific concrete mix proportions are summarized in Table 1. Concrete was cast in two standard plastic molds with dimensions of 100 by $200 \mathrm{~mm}$ and 150 by $300 \mathrm{~mm}$ and placed in a curing chamber within 30 minutes. Plastic molds were removed after $24 \mathrm{~h}$ and specimens were cured in a water pond. A series of static and dynamic tests were conducted at different ages: $4,7,14$, and 28 days. One day before testing, ten 100 by $200 \mathrm{~mm}$ and 150 by $300 \mathrm{~mm}$ cylinders for each test series were taken out of a water pond and air-cured in a constant temperature-and-humidity room. 
TABLE 1: Mix proportions of concrete design.

\begin{tabular}{|c|c|c|c|c|c|c|c|c|c|c|c|}
\hline \multirow{3}{*}{ ID } & \multirow{3}{*}{ Cement type } & \multirow{3}{*}{$\mathrm{W} / \mathrm{B}$} & \multirow{3}{*}{$\mathrm{S} / \mathrm{A}$} & \multicolumn{8}{|c|}{ Unit quantity $\left(\mathrm{kg} / \mathrm{m}^{3}\right)$} \\
\hline & & & & \multirow{2}{*}{ W } & \multirow{2}{*}{$\mathrm{C}$} & \multirow{2}{*}{ S } & \multirow{2}{*}{$\mathrm{G}$} & \multicolumn{2}{|c|}{ Mineral admixture } & \multicolumn{2}{|c|}{ Chemical admixture } \\
\hline & & & & & & & & FA & GBFS & AE (binder \%) & SP (binder \%) \\
\hline Mix 1 & & 0.45 & 0.46 & 259 & 121 & 777 & 934 & 58 & 69 & 0.9 & - \\
\hline Mix 2 & Type I & 0.35 & 0.47 & 308 & 166 & 761 & 886 & 81 & 85 & - & 1 \\
\hline Mix 3 & & 0.3 & 0.46 & 357 & 165 & 714 & 868 & 94 & 99 & - & 1 \\
\hline
\end{tabular}

Note. W: water; C: cement; S: sand; G: gravel; FA: fly ash; GBFS: granulated blast furnace slag; AE: air-entraining agent; SP: superplasticizer.

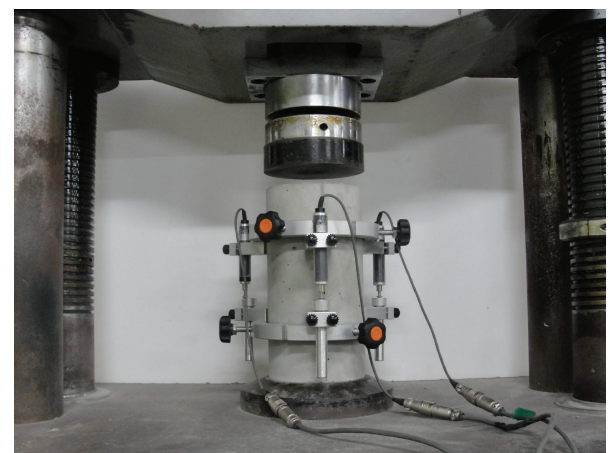

FIGURE 1: Testing setup and instrumentation for the uniaxial compressive test of a concrete cylinder.

2.2. Static Tests for Compressive Strength and Elastic Modulus. The cylinders were ground at both ends before testing to remove any surface irregularity as well as ensure the ends to be perpendicular to the sides of the specimen. Elastic modulus and compressive strength of the cylinders were measured using a Universal Testing Machine (UTM) with a capacity of $1000 \mathrm{kN}$ according to ASTM C469 [4] and ASTM C39 [25], respectively. Tests were performed at a loading rate of approximately $0.28 \mathrm{MPa} / \mathrm{s}$. Deformations were measured using three sets of linear voltage differential transducers attached to two fixed rings (see Figure 1). The apparatus consisted of two aluminum rings with screws for attachment to the specimen. The spacing between screws on the top and bottom rings was $70 \mathrm{~mm}$ and $150 \mathrm{~mm}$ for 100 by $200 \mathrm{~mm}$ and 150 by $300 \mathrm{~mm}$ cylinders, respectively, which served as a gauge length for calculating axial strain from the measured deformations. The static elastic modulus of concrete is defined as a chord modulus from the stress-strain curve with a first point at strain level of $0.00005\left(\varepsilon_{1}\right)$ and second point at $40 \%$ of the maximum stress as follows:

$$
E_{c}=\frac{0.4 f_{c}-\sigma\left(\varepsilon_{1}\right)}{\varepsilon\left(0.4 f_{c}\right)-\varepsilon_{1}}
$$

2.3. Dynamic Tests for Estimating Dynamic Elastic Modulus. Dynamic elastic modulus of concrete was estimated by measuring fundamental longitudinal and transverse resonance frequencies of cylinders in accordance with ASTM C215 [16]. Shown in Figure 2(a) is the test setup and data acquisition system for the transverse resonance frequency test. For the longitudinal resonance frequency test, an accelerometer was placed on the center of one concrete surface, and an impact source was hit on the center of the other concrete surface. A steel ball having a diameter of $10 \mathrm{~mm}$ was used as an impact source for generating incident stress waves in a concrete specimen: the steel ball was effective for generating wideband frequency signals from very low to $20 \mathrm{kHz}$, which covers a frequency range of the resonance tests for the 100 by $200 \mathrm{~mm}$ and 150 by $300 \mathrm{~mm}$ cylinders in this study. Dynamic response of concrete cylinder was measured by an accelerometer attached to concrete specimen according to ASTM C215 [16]. Resulting time signals were converted to the frequency domain using the FFT (Fast Fourier Transformation) algorithm. The resonance frequencies of concrete are manifested as dominant amplitude in the frequency domain. The most dominant frequency was regarded as fundamental resonance frequencies of longitudinal (or transverse) mode. Dynamic elastic moduli based on the fundamental longitudinal frequency $\left(E_{d, L R}\right)$ were estimated using the following equation:

$$
E_{d, L R}=\beta_{L} M f_{L}^{2}(\mathrm{~Pa}),
$$

where $\beta_{L}$ is constant dependent on dimensions and Poisson's ratio of concrete specimen $\left(=5.093\left(L / D^{2}\right)\right)$ for a cylinder in $\mathrm{N} \cdot \mathrm{s}^{2}\left(\mathrm{~kg} \cdot \mathrm{m}^{2}\right), M$ is mass of specimen in $\mathrm{kg}$, and $f_{L}$ is fundamental longitudinal resonance frequency in $\mathrm{Hz}$. In addition, dynamic elastic moduli of concrete based on the fundamental transverse frequency $\left(E_{d, T R}\right)$ were estimated using the following equation:

$$
E_{d, T R}=\beta_{T} M f_{T}^{2}(\mathrm{~Pa}),
$$

where $\beta_{T}$ is constant dependent on dimensions of concrete cylinder $\left(=1.6067\left[L^{3} T / D^{4}\right]\right.$ for a cylinder, and $T$ is a correction factor dependent on ratio of the radius of gyration $K$ to the height of specimen $H$ [for concrete cylinder $K / H=$ $D / 4 H]$ and Poisson's ratio) in $\mathrm{N} \cdot \mathrm{s}^{2}\left(\mathrm{~kg} \cdot \mathrm{m}^{2}\right)$ and $f_{T}$ is fundamental transverse resonance frequency in $\mathrm{Hz}$.

For comparison purposes, the $P$-wave velocity of concrete, $C_{P}$, was measured according to ASTM C597 [26] using a pair of $P$-wave transducers (see Figure 2(b)), each of which generates and receives a longitudinal ultrasonic pulse of about $52 \mathrm{kHz}$ through a concrete cylinder. Dynamic elastic modulus based on $C_{P}\left(E_{d, P}\right)$ is determined using the following equation:

$$
E_{d, P}=\alpha_{P} \rho C_{P}^{2},
$$

where $\alpha_{P}$ is constant dependent on Poisson's ratio $v$, that is, $(1+v)(1-2 v) /(1-v)$. 


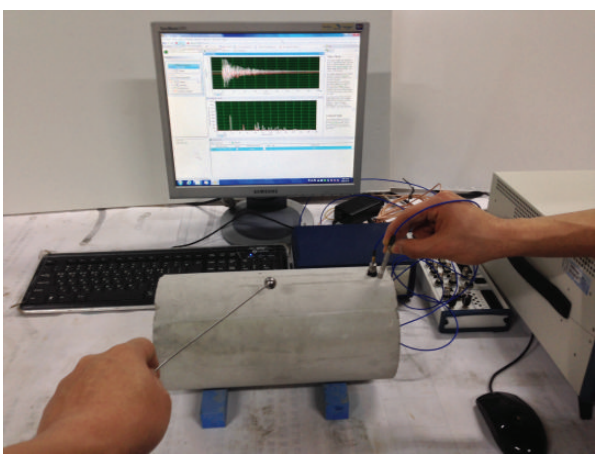

(a)

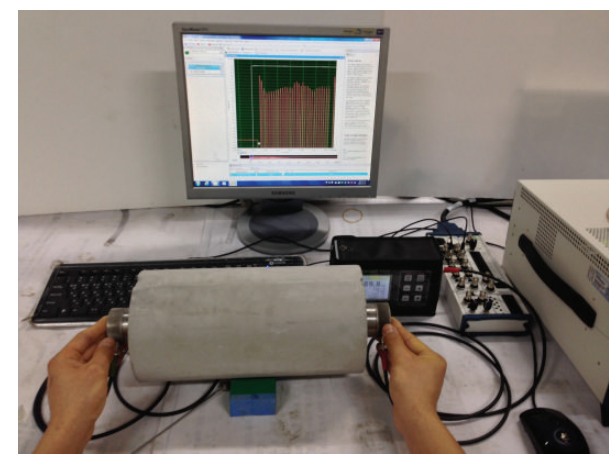

(b)

FIGURE 2: Test setups and data acquisition system for evaluating dynamic elastic moduli using two different nondestructive evaluation tests: (a) resonance frequency test (transverse mode) and (b) ultrasonic pulse velocity test (longitudinal mode).

TABLE 2: Summary of test results measured from 100 by $200 \mathrm{~mm}$ and 150 by $300 \mathrm{~mm}$ cylinders.

\begin{tabular}{|c|c|c|c|c|c|c|c|c|c|c|c|c|}
\hline \multirow{2}{*}{ Cylinder size } & \multirow{2}{*}{ Mix } & \multirow{2}{*}{ Day } & \multicolumn{2}{|c|}{$F_{c}$} & \multicolumn{2}{|c|}{$E_{c}$} & \multicolumn{2}{|c|}{$C_{p}$} & \multicolumn{2}{|c|}{$\overline{f_{L}}$} & \multicolumn{2}{|c|}{$\overline{f_{T}}$} \\
\hline & & & $\mu[\mathrm{MPa}]$ & COV [\%] & $\mu[\mathrm{GPa}]$ & COV [\%] & $\mu[\mathrm{m} / \mathrm{s}]$ & $\mathrm{COV}$ [\%] & $\mu[\mathrm{Hz}]$ & COV [\%] & $\mu[\mathrm{Hz}]$ & COV [\%] \\
\hline \multirow{12}{*}{$100 \times 200$} & \multirow{4}{*}{ Mix 1} & D4 & 7.76 & 0.96 & 9.6 & 3.50 & 3327 & 2.05 & 6845 & 1.32 & 4165 & 1.86 \\
\hline & & D7 & 10.3 & 3.64 & 11.6 & 7.70 & 3511 & 1.18 & 7220 & 1.28 & 4455 & 2.38 \\
\hline & & D14 & 14.4 & 2.44 & 15.4 & 10.62 & 3855 & 0.82 & 7795 & 1.58 & 4810 & 1.29 \\
\hline & & D28 & 18.9 & 5.05 & 15.7 & 5.41 & 4032 & 1.24 & 8420 & 0.66 & 5165 & 1.15 \\
\hline & \multirow{4}{*}{ Mix 2} & D4 & 25.6 & 3.50 & 16.6 & 2.54 & 3803 & 1.10 & 8360 & 0.95 & 5160 & 1.55 \\
\hline & & D7 & 29.3 & 3.40 & 17.0 & 2.10 & 4108 & 0.83 & 8570 & 0.53 & 5215 & 0.74 \\
\hline & & D14 & 36.7 & 2.25 & 19.1 & 2.44 & 4224 & 1.42 & 8995 & 1.32 & 5455 & 1.19 \\
\hline & & D28 & 39.3 & 3.63 & 23.1 & 3.18 & 4375 & 1.25 & 9280 & 0.91 & 5690 & 1.41 \\
\hline & \multirow{4}{*}{ Mix 3} & D4 & 22.9 & 3.79 & 1654 & 4.60 & 3978 & 1.90 & 8365 & 1.17 & 5150 & 1.37 \\
\hline & & D7 & 28.2 & 4.59 & 19.8 & 8.21 & 4122 & 0.92 & 8730 & 0.52 & 5335 & 1.32 \\
\hline & & D14 & 34.0 & 5.75 & 20.4 & 3.23 & 4261 & 1.21 & 8995 & 1.01 & 5445 & 1.33 \\
\hline & & D28 & 40.8 & 5.76 & 22.3 & 5.82 & 4361 & 1.04 & 9185 & 1.96 & 5555 & 3.05 \\
\hline \multirow{12}{*}{$150 \times 300$} & \multirow{4}{*}{ Mix 1} & D4 & 7.7 & 2.75 & 10.4 & 7.33 & 3223 & 2.16 & 4585 & 0.98 & 2800 & 0.80 \\
\hline & & D7 & 10.1 & 3.63 & 12.2 & 6.56 & 3487 & 1.53 & 4870 & 1.31 & 3015 & 1.66 \\
\hline & & D14 & 13.8 & 3.55 & 14.7 & 7.08 & 3723 & 1.39 & 5220 & 1.15 & 3215 & 1.21 \\
\hline & & D28 & 19.3 & 4.34 & 15.7 & 5.23 & 3937 & 1.42 & 5600 & 1.38 & 3430 & 1.16 \\
\hline & \multirow{4}{*}{ Mix 2} & D4 & 24.9 & 3.02 & 16.6 & 5.67 & 3934 & 1.47 & 5630 & 1.32 & 3450 & 1.74 \\
\hline & & D7 & 29.9 & 2.60 & 17.5 & 3.32 & 4067 & 1.59 & 5730 & 0.89 & 3485 & 1.58 \\
\hline & & D14 & 36.9 & 4.37 & 20.9 & 2.26 & 4219 & 0.72 & 6010 & 0.73 & 3645 & 1.29 \\
\hline & & D28 & 43.2 & 4.92 & 23.7 & 3.37 & 4296 & 0.99 & 6200 & 0.81 & 3800 & 1.02 \\
\hline & \multirow{4}{*}{ Mix 3} & D4 & 23.1 & 2.33 & 16.9 & 3.44 & 3922 & 1.23 & 5605 & 0.84 & 3435 & 0.93 \\
\hline & & D7 & 29.0 & 1.50 & 18.7 & 2.22 & 4056 & 0.84 & 5825 & 1.10 & 3535 & 1.10 \\
\hline & & D14 & 39.7 & 2.84 & 21.5 & 7.09 & 4192 & 0.97 & 6060 & 0.81 & 3675 & 0.91 \\
\hline & & D28 & 44.4 & 4.47 & 21.3 & 7.21 & 4295 & 0.63 & 6260 & 1.17 & 3820 & 1.33 \\
\hline
\end{tabular}

\section{Result and Discussion}

3.1. Experimental Variability. In this study, the coefficient of variation (COV, the standard deviation, $\sigma$, divided by the mean value, $\mu$, of a set of samples) was used as a means of evaluating the experimental variability of compressive strength and static and dynamic properties of concrete. Table 2 compares the statistical parameters $(\mu$ and COV) of test results
$\left(F_{c}, E_{c}, C_{p}, f_{L}\right.$, and $\left.f_{T}\right)$ obtained from 100 by $200 \mathrm{~mm}$ and 150 by $300 \mathrm{~mm}$ cylinders.

The average COVs of the compressive strength of concrete $F_{c}$ from different mix proportions and testing ages are $4.41 \%$ and $3.65 \%$ for 100 by $200 \mathrm{~mm}$ and 150 by $300 \mathrm{~mm}$ cylinders, respectively. The 100 by $200 \mathrm{~mm}$ cylinders have about $10 \%$ higher within-test variability than 150 by $300 \mathrm{~mm}$ cylinders. The result is consistent with the observation by 
previous researchers that 100 by $200 \mathrm{~mm}$ cylinder tends to have about $20 \%$ higher within-test variability than 150 by $300 \mathrm{~mm}$ cylinder [27]. The COVs from the 150 by $300 \mathrm{~mm}$ cylinder are between good (4.0 to 5.0) and excellent $(<2.0)$ categories according to ACI 214R [28], whereas for 100 by $200 \mathrm{~mm}$ cylinder the COVs are between fair (5.0 to 6.0) and excellent categories.

The average COVs of the static elastic modulus $E_{c}$ from 100 by $200 \mathrm{~mm}$ and 150 by $300 \mathrm{~mm}$ cylinders are $6.32 \%$ and $5.83 \%$, respectively. A slightly higher COV of $E_{c}$ is mainly due to imperfect concrete specimens and testing procedure: the opposite faces of the specimens were slightly skew and their deformations under compression were not uniform. This may also affect compressive strength of concrete but appears to be more influential to determination of elastic modulus. Table 2 shows that the COVs of both $F_{c}$ and $E_{c}$ from the three different mixes are reasonably consistent at different ages in $4,7,14$, and 28 days.

For the dynamic tests, the 100 by $200 \mathrm{~mm}$ cylinders produce equivalent or slightly higher variability than the 150 by $300 \mathrm{~mm}$ cylinders: however, the differences appear to be insignificant. The average COVs of the fundamental longitudinal $f_{L}$ and transverse $f_{T}$ frequencies measured from 100 by $200 \mathrm{~mm}$ and 150 by $300 \mathrm{~mm}$ cylinders are $1.64 \%$ and $1.20 \%$, and $1.62 \%$ and $1.17 \%$, respectively. Furthermore, the average COVs of the $P$-wave velocity $\left(C_{L}\right)$ for 100 by $200 \mathrm{~mm}$ and 150 by $300 \mathrm{~mm}$ cylinders are $1.40 \%$ and $1.23 \%$, respectively, both of which are consistent with observations by ACI committee 228 [29].

3.2. Compressive Strength. Figure 3 compares compressive strengths of concrete cylinders measured from 100 by $200 \mathrm{~mm}$ and 150 by $300 \mathrm{~mm}$ cylinders $\left(F_{c 100}\right.$ and $F_{c 150}$, resp.). The experimental data, represented as open symbols, show that there is no significant difference between $F_{c 100}$ and $F_{c 150}$ in the lower strength range of $8 \mathrm{MPa}$ to $30 \mathrm{MPa}$, with a mean absolute error (MAE) less than $1 \mathrm{MPa}$. In this study, MAE was defined as follows:

$$
\mathrm{MAE}=\frac{\sum\left|F_{c 150}-F_{c 100}\right|}{N}
$$

where $N$ is the number of the experimental data (i.e., in this study $N=120$ ). The result for low compressive strength is consistent with observations by prior researchers $[22,24,30]$.

However, it was noticed that scattering of experimental data in this study becomes greater as compressive strength increases in the higher strength range greater than $30 \mathrm{MPa}$. $F_{c 150}$-to- $F_{c 100}$ ratio in this study gradually increases as $F_{c 100}$ increases. An approximated equation that relates $F_{c 150}$ and $F_{c 100}$ was established by a linear regression analysis of the experimental data set in this study as follows:

$$
F_{c 150}=1.11 F_{c 100}-1.56[\mathrm{MPa}] \quad\left(R^{2}=0.96\right) .
$$

The best-fit line, presented as a red dash line in Figure 3, is compatible with the equations proposed by prior researchers $[19,20]$. However, there is contradiction in the relationship between $F_{c 150}$ and $F_{c 100}$ reported by different researchers (see

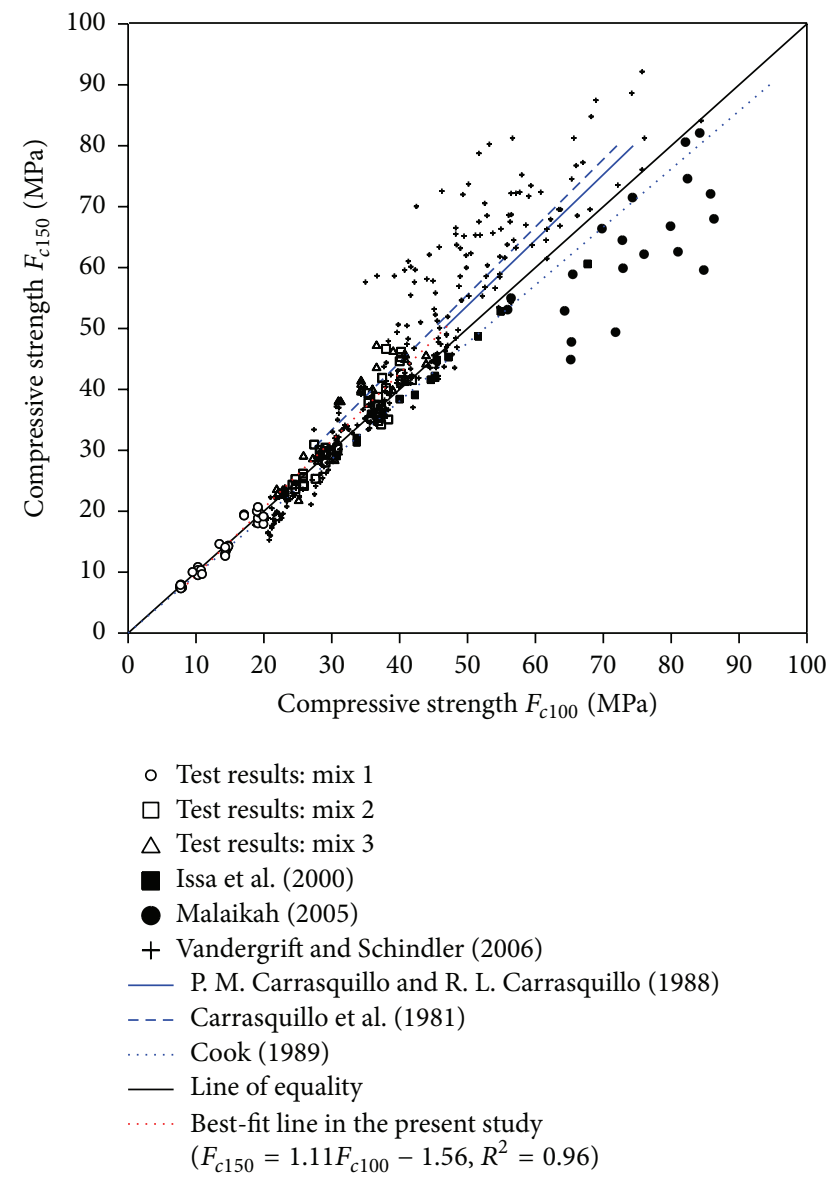

FIGURE 3: Comparison of compressive strength of concrete measured from 100 by $200 \mathrm{~mm}$ and 150 by $300 \mathrm{~mm}$ cylinders $\left(F_{c 100}\right.$ and $F_{c 150}$, resp.).

Figure 2) $[18-22,24,30]$. The inconsistency results in the higher strength range are attributed to complexity in the interfacial transition zone of concrete $[10,24]$. It is known that considerable stresses are transferred at cement paste and aggregates' interface of high strength concrete due to lower porosity of the interfacial transition zone (ITZ). In fact, there are a number of factors affecting the ITZ, which include coarse aggregates, mineral admixtures, and curing methods, and various factors affect compressive strength in different ways for different cylinder sizes [14]. Therefore, special care is still needed for selecting the cylinder size for measuring compressive strength of relatively high strength concrete $(>40 \mathrm{MPa})$.

3.3. Static Elastic Moduli. Figure 4 compares static elastic moduli of concrete measured from 100 by $200 \mathrm{~mm}$ and 150 by $300 \mathrm{~mm}$ cylinders $\left(E_{c 100}\right.$ and $E_{c 150}$, resp.) in this study. For a comparison, database collected from the literature $[22,30]$ was shown in the same figure. The experimental data set in this study, presented as open symbols, shows that $E_{c 100}$ is closely correlated with $E_{c 150}$ in the elastic modulus range of $10 \mathrm{GPa}$ to $25 \mathrm{GPa}$. For the lower elastic modulus range of 10 to $15 \mathrm{GPa}, E_{c 100}$ values are comparable with $E_{c 150}$ values, with 


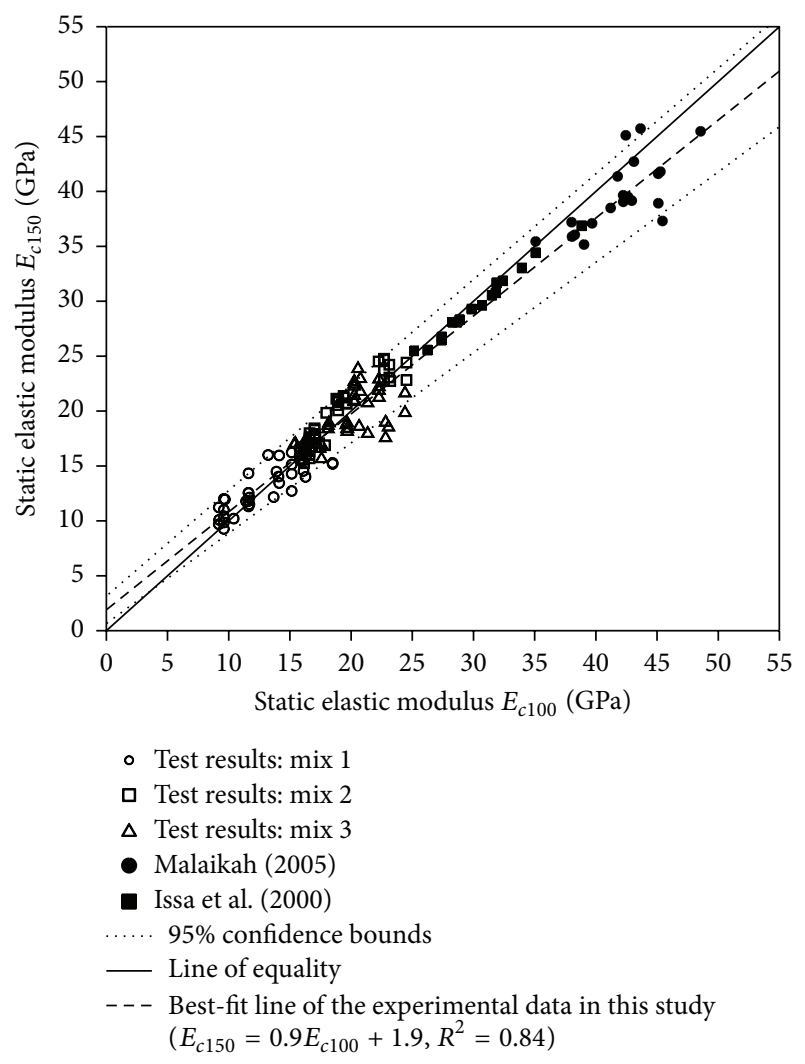

FIGURE 4: Comparison of static elastic moduli of concrete measured from 100 by $200 \mathrm{~mm}$ and 150 by $300 \mathrm{~mm}$ cylinders $\left(E_{c 100}\right.$ and $E_{c 150}$, resp.).

MAE between $E_{c 100}$ and $E_{c 150}$ of about $0.45 \mathrm{GPa}$. Therefore, it may be acceptable to assume from a practical perspective that static elastic moduli using 100 by $200 \mathrm{~mm}$ and 150 by $300 \mathrm{~mm}$ cylinders are equivalent.

However, the ratio of $E_{c 150}$ to $E_{c 100}$ appears to gradually increase as $E_{c 150}$ increases to $25 \mathrm{GPa}$. The higher elasticity in the smaller size is attributed to the fact that the quantity of mortar required to fill the space between the particles of the coarse aggregate and the wall of the mold is greater than that necessary in the interior of the mass (i.e., wall effect) [10]. In general, the elasticity of cement mortar is greater than that of concrete, which consequently results in increasing the effective elasticity of concrete in smaller size. In this study, the best-fit line that approximates the relationship between $E_{c 150}$ and $E_{c 100}$ was established by a linear regression analysis as follows:

$$
E_{c 150}=0.9 E_{c 100}+1.9[\mathrm{MPa}] \quad\left(R^{2}=0.84\right)
$$

The best-fit line and 95\% confidence bounds of the best-fit line are presented as solid and dash lines, respectively, in Figure 3. Interestingly, the best-fit line of the experimental data in this study $\left(10 \mathrm{GPa} \leq E_{c 100} \leq 25 \mathrm{GPa}\right)$ appears to be valid for predicting the data set in the higher elastic modulus range of $25 \mathrm{GPa}$ to $55 \mathrm{GPa}$ reported by prior researchers [22, 30]. However, it is still difficult to attain general conclusions on the relationship between $E_{c 150}$ and $E_{c 100}$, especially for

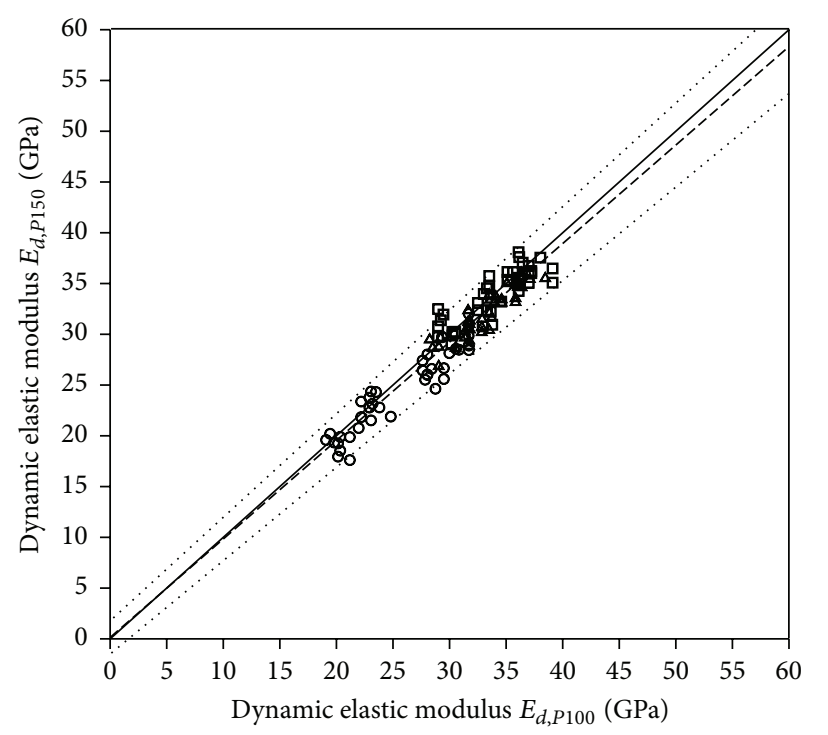

$$
\begin{aligned}
& \circ \text { Test results: } \operatorname{mix} 1 \\
& \square \text { Test results: } \operatorname{mix} 2 \\
& \triangle \text { Test results: } \operatorname{mix} 3 \\
& \ldots . . \quad 95 \% \text { confidence bounds } \\
& - \text { Line of equality } \\
& -- \text { Best-fit line for experimental data in this study } \\
& \quad\left(E_{d, P 150}=0.97 E_{d, P 100}+0.138, R^{2}=0.92\right)
\end{aligned}
$$

FIGURE 5: Comparison of velocity moduli from 100 by $200 \mathrm{~mm}$ and 150 by $300 \mathrm{~mm}$ cylinders.

concrete in the higher strength range greater than $50 \mathrm{MPa}$, because of scarcity of available experimental data.

3.4. Dynamic Elastic Moduli. Figure 5 compares dynamic elastic moduli measured using UPV tests (i.e., velocity moduli) from 100 by $200 \mathrm{~mm}$ and 150 by $300 \mathrm{~mm}$ cylinders $\left(E_{d, P 100}\right.$ and $E_{d, P 150}$, resp.) in accordance with ASTM C597 [26]. It was observed that 100 by $200 \mathrm{~mm}$ cylinders consistently result in slightly higher dynamic elastic moduli than 150 by $300 \mathrm{~mm}$ cylinders. Linear regression of $E_{d, P 100}$ and $E_{d, P 150}$ measured in this study shows that $E_{d, P 100}$ is about $3 \%$ greater than $E_{d, P 150}$ in a range of $20 \mathrm{GPa}$ to $40 \mathrm{GPa}$ (see Figure 5). The MAE from two different cylinders was about $0.5 \mathrm{GPa}$, which is only $25 \%$ of the MAE from static elastic moduli in this study (i.e., $2 \mathrm{GPa}$ ).

In addition, shown in Figures 6(a) and 6(b) is the comparison of dynamic elastic moduli measured from longitudinal and transverse resonance frequency tests (i.e., resonance moduli), $E_{d, L R}$ and $E_{d, T R}$, respectively, from 100 by $200 \mathrm{~mm}$ and 150 by $300 \mathrm{~mm}$ cylinders in accordance with ASTM C125 [16]. The use of 150 by $300 \mathrm{~mm}$ cylinders tends to result in slightly higher resonance moduli (both $E_{d, L R}$ and $E_{d, T R}$ ) than those from 100 by $200 \mathrm{~mm}$ cylinders. According to the linear regression analysis, it was found that the resonance moduli measured using the 150 by $300 \mathrm{~mm}$ cylinder $\left(E_{d, L R 150}\right.$ or $\left.E_{d, R R 150}\right)$ are 1 to $2 \%$ greater than those from the 100 by $200 \mathrm{~mm}$ cylinder $\left(E_{d, L R 100}\right.$ or $\left.E_{d, R R 100}\right)$. Approximated equations that relate the resonance moduli from the two different cylinder sizes are shown in Figures 6(a) and 6(b). 


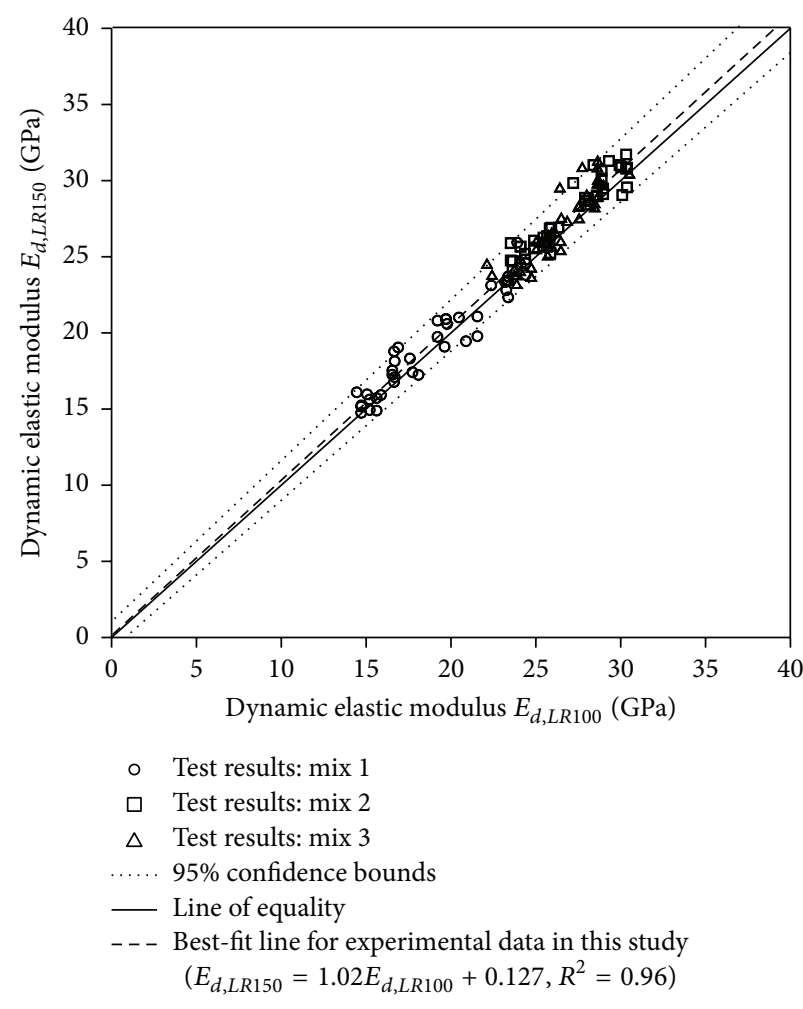

(a)
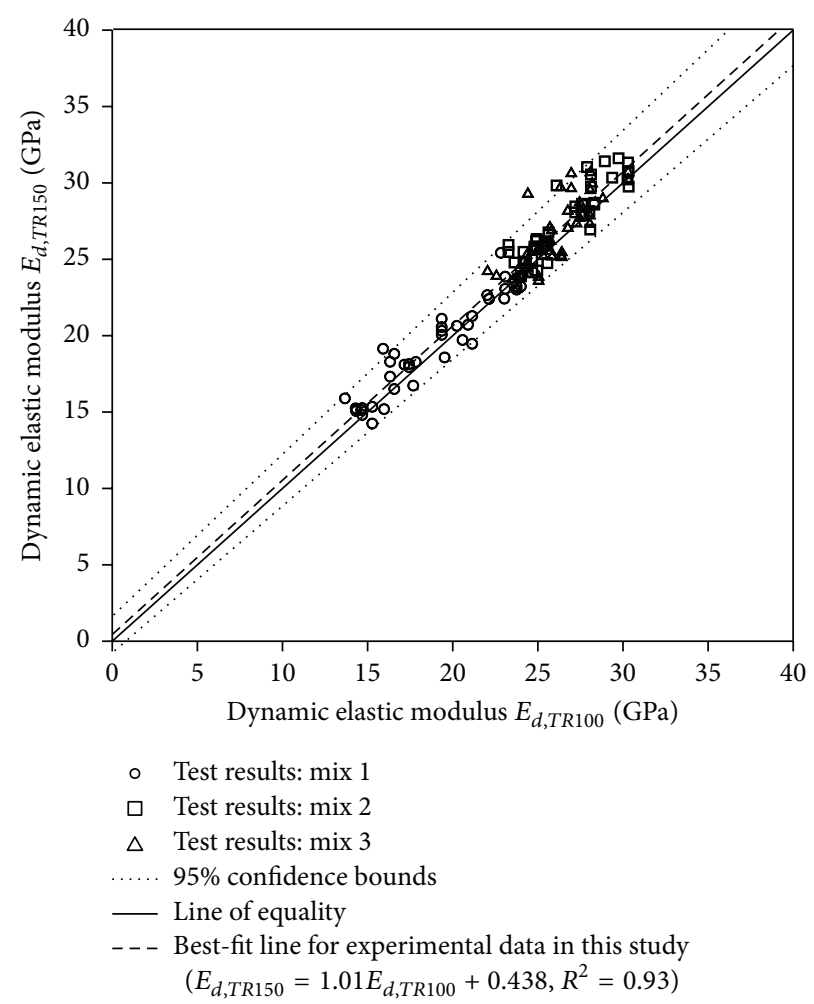

(b)

FIGURE 6: Comparison of resonance moduli from 100 by $200 \mathrm{~mm}$ and 150 by $300 \mathrm{~mm}$ cylinders: (a) $E_{d, L R 150}$ versus $E_{d, L R 100}$ and (b) $E_{d, T R 150}$ versus $E_{d, T R 100}$.

Furthermore, without regard to longitudinal or transverse modes, the MAE between the resonance moduli from the different cylinder is less than $0.3 \mathrm{GPa}$. Therefore, the findings in this study demonstrate that the dynamic elastic moduli (both velocity and resonance moduli) using the 100 by $200 \mathrm{~mm}$ and 150 by $300 \mathrm{~mm}$ cylinders are regarded as being equal from a practical standpoint.

However, it was observed that there is a precaution in measuring reliable and consistent resonance frequency using the 100 by $200 \mathrm{~mm}$ cylinder. The smaller cylinder has higher chance of mistakenly hitting an impact source (location and inclination to test surface), which may cause undesirable resonance modes such as torsional modes in the frequency domain. Consequently, it was often difficult to select a right frequency peak corresponding to the fundamental longitudinal or transverse modes. In this study, preliminary numerical simulations were conducted to calculate theoretical frequency peak values, which was helpful to select a right frequency peak. In addition, to improve accuracy and consistency, resonance tests were repeated until the COV of five successive testing procedures is less than $5 \%$, and average of the five test results was finally accepted in this study.

3.5. Relationship between Static Elastic Modulus and Compressive Strength. Figure 7 is a plot representing relationship between static elastic modulus and compressive strength measured in accordance with ASTM C469 [4] and ASTM
C39 [25], respectively. The data points obtained from 100 by $200 \mathrm{~mm}$ and 150 by $300 \mathrm{~mm}$ cylinders are presented as open and solid symbols in Figures 7(a) and 7(b), respectively. For a comparison, Figure 7 presents three code equations adopted by ACI 318 and ACI 363 committees and CEB-FIP Model code and a practical equation proposed by Noguchi et al. [8] (see (14)), which was developed based on an extensive experimental database from normal to high strength concrete:

$$
E_{c}=k_{1} k_{2} 33500\left(\frac{F_{c}}{60}\right)^{1 / 3}\left(\frac{w_{c}}{2400}\right)^{2},
$$

where $k_{1}$ and $k_{2}$ are correction factors for coarse aggregates and mineral admixtures.

It was found that the effect of cylinder size appears to be insignificant on the relationship between static elastic modulus and compressive strength of concrete for normal strength concrete $(<40 \mathrm{MPa})$ in this study. Approximated equations that relate $E_{c}$ and $F_{c}$ from 100 by $200 \mathrm{~mm}$ and 150 by $300 \mathrm{~mm}$ cylinders were established by nonlinear regression analyses and shown in Figures 7(a) and 7(b), respectively. The MAE of the two best-fit curves is less than $0.1 \mathrm{GPa}$ in the compressive strength range of $10 \mathrm{MPa}$ to $40 \mathrm{MPa}$. In this study, MAE of the two continuous curves was defined as follows:

$$
\mathrm{MAE}_{\text {con }}=\frac{\left[\int g_{1}\left(F_{c}\right)-g_{2}\left(F_{c}\right) d F_{c}\right]}{\int d F_{c}},
$$




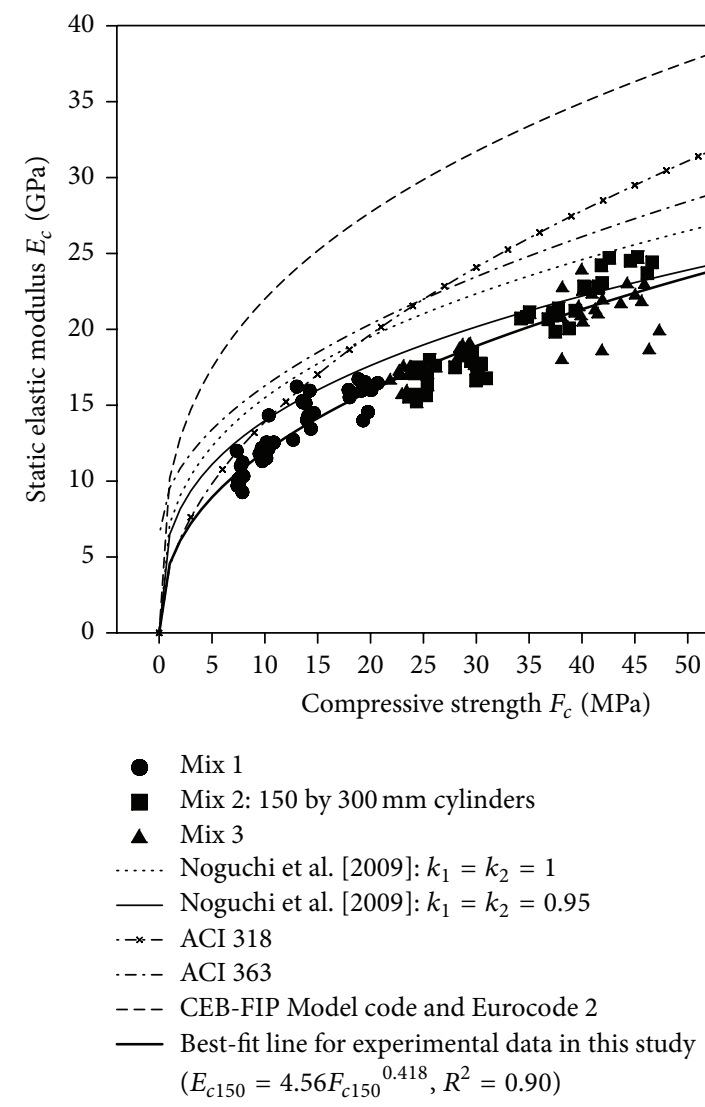

(a)

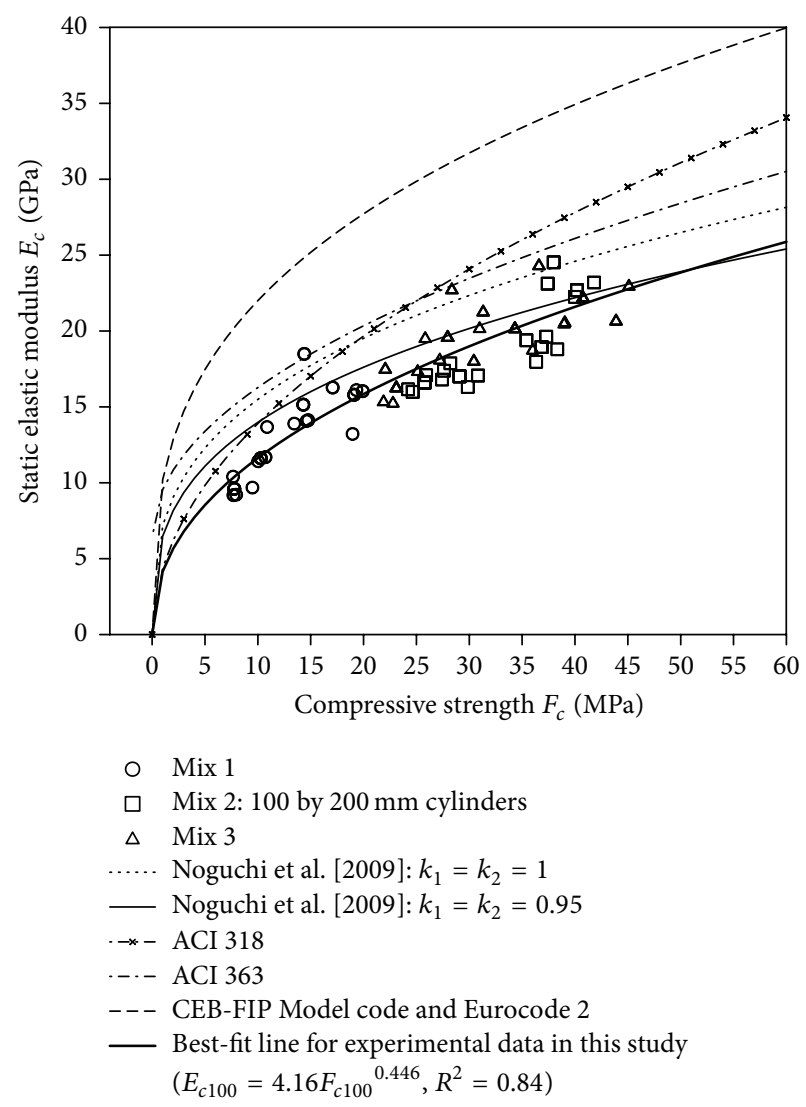

(b)

FIGURE 7: Comparison of compressive strength and static elastic modulus of concrete.

where $\mathrm{MAE}_{\text {con }}$ is mean average error (MAE) of two continuous functions, $g_{i}$ is a function presenting $E_{c}$ expressed as $F_{c}$, and the subscript $i$ indicates cylinder size ( 1 and 2 for the 100 by $200 \mathrm{~mm}$ and 150 by $300 \mathrm{~mm}$ cylinders, resp.). Furthermore, there is no significant difference in $R^{2}$ values of the two best-fit curves: $R^{2}$ values for the 100 by $200 \mathrm{~mm}$ and 150 by $300 \mathrm{~mm}$ cylinders are 0.88 and 0.90 , respectively. Therefore, the 100 by $200 \mathrm{~mm}$ cylinders can be used instead of 150 by $300 \mathrm{~mm}$ cylinders to estimate static elastic modulus from compressive strength without reducing accuracy and consistency. However, the three code equations tend to overestimate static modulus of concrete compared to those from direct measurement according to ASTM C469 [4]. As summarized in Table 3, mean average error (MAE) between measured and predicted $E_{c}$ from the three code equations is in a range of 4.4 to $12 \mathrm{GPa}$, corresponding to about $10 \%$ to $30 \%$ of the measured $E_{c}$. In contrast, the Noguchi equation [8] predicts experimental results with far more improved accuracy (i.e., MAE less than $2 \mathrm{GPa}$ ) by addressing correction factors for the effects of aggregates and mineral admixtures (i.e., $k_{1}=k_{2}=0.95$ ).

3.6. Relationship between Static and Dynamic Elastic Moduli. Figure 8 presents the relationship between static and dynamic elastic moduli determined using different nondestructive testing methods, $E_{d, P}, E_{d, L R}$, and $E_{d, T R}$, respectively, with
TABLE 3: Mean absolute error (MAE) of expressions relating static elastic modulus and compressive strength measured using 100 by $200 \mathrm{~mm}$ and 150 by $300 \mathrm{~mm}$ cylinders.

\begin{tabular}{|c|c|c|}
\hline \multirow[b]{2}{*}{$\begin{array}{l}\text { Equation to convert } E_{d} \text { to } \\
E_{c}\end{array}$} & \multicolumn{2}{|c|}{$\operatorname{MAE}(\mathrm{GPa})$} \\
\hline & $\begin{array}{c}150 \text { by } 300 \mathrm{~mm} \\
\text { cylinder } \\
E_{d, L T} \\
\end{array}$ & $\begin{array}{c}100 \text { by } 200 \mathrm{~mm} \\
\text { cylinder } \\
E_{d, L T} \\
\end{array}$ \\
\hline Equation (1) & 4.83 & 4.63 \\
\hline Equation (2) & 4.54 & 4.43 \\
\hline Equation (3) & 12.21 & 12.15 \\
\hline $\begin{array}{l}\text { Equation (14) with } \\
k_{1}=k_{2}=1\end{array}$ & 3.42 & 3.41 \\
\hline $\begin{array}{l}\text { Equation (14) with } \\
k_{1}=k_{2}=0.95\end{array}$ & 1.56 & 1.88 \\
\hline Best-fit line & 1.32 & 1.57 \\
\hline
\end{tabular}

Poisson's ratio of 0.2 . The use of Poisson's ratio of 0.2 is reasonable for common concrete in practice [10]. In Figure 8, $E_{d, P}$, $E_{d, L R}$, and $E_{d, T R}$ measured from 100 by $200 \mathrm{~mm}$ and 150 by $300 \mathrm{~mm}$ cylinders are shown as open and solid symbols in left and right columns. For comparison purposes, several wellknown empirical equations (see (3), (4), and (5)) proposed by prior researchers are shown in the figures. 

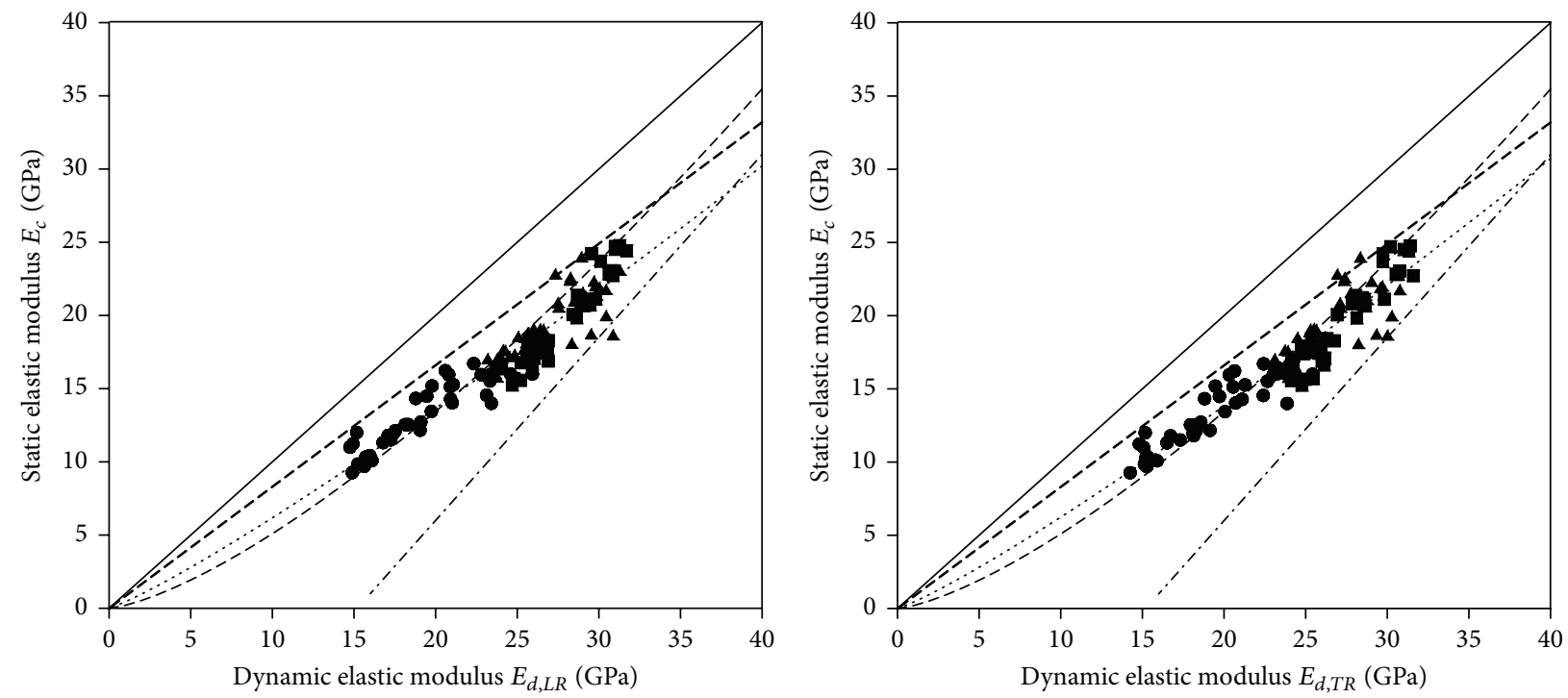

- Mix $1(150 \times 300 \mathrm{~mm})$

- Mix $2(150 \times 300 \mathrm{~mm})$

- Mix $3(150 \times 300 \mathrm{~mm})$

— Line of equality

--- Lydon and Balendran (1986)

-..- BS8100 Part 2

--- Popovics (1975)

…. Best-fit line for experimental data in this study $\left(E_{c 150}=0.44 E_{d, L R 150}^{1.15}, R^{2}=0.90\right)$

(a)
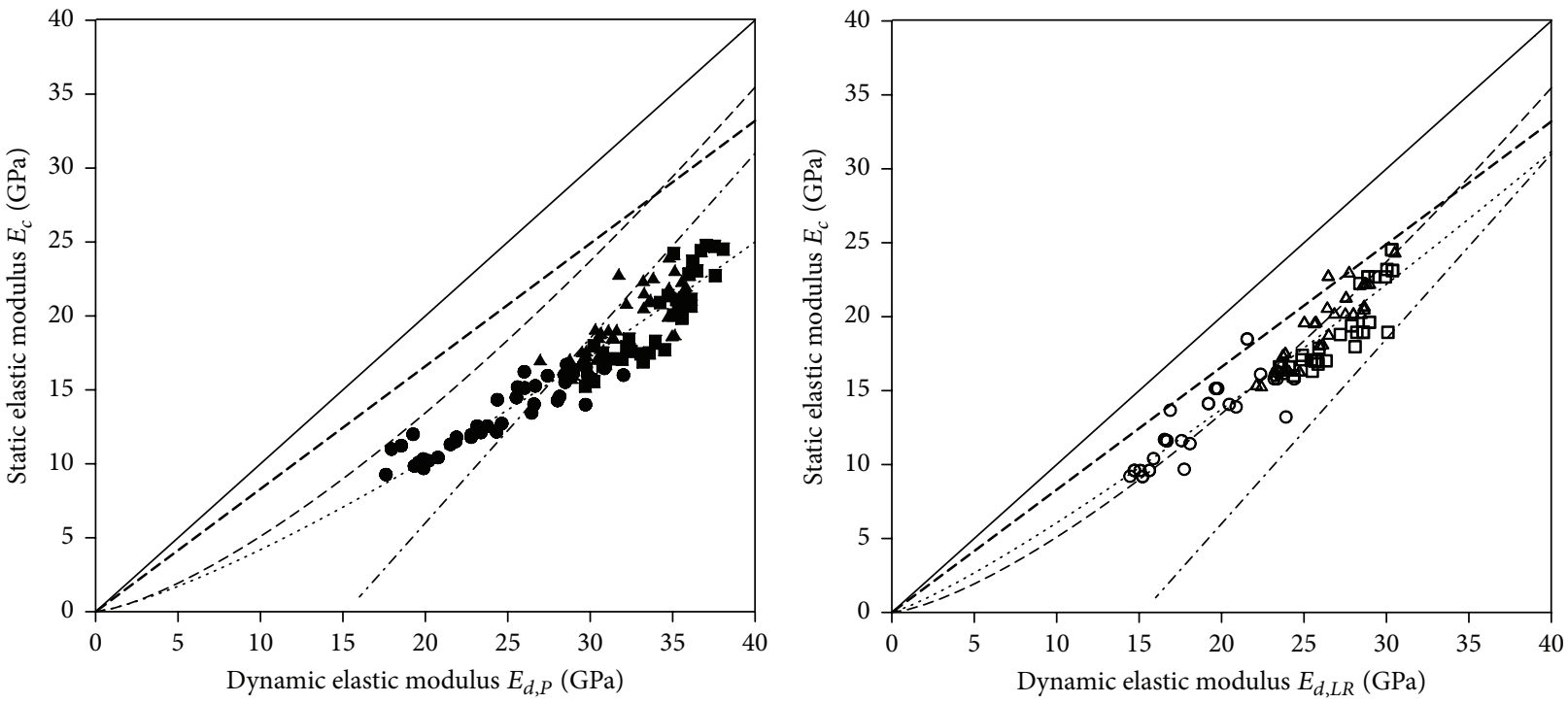

- $\quad \operatorname{Mix} 1(150 \times 300 \mathrm{~mm})$

- Mix $2(150 \times 300 \mathrm{~mm})$

- Mix $3(150 \times 300 \mathrm{~mm})$

_ Line of equality

--- Lydon and Balendran (1986)

...- BS8100 Part 2

- - Popovics (1975)

..... Best-fit line for experimental data in this study $\left(E_{c 150}=0.22 E_{d, P 150}^{1.29}, R^{2}=0.87\right)$

- $\operatorname{Mix} 1(150 \times 300 \mathrm{~mm})$

- $\operatorname{Mix} 2(150 \times 300 \mathrm{~mm})$

- Mix $3(150 \times 300 \mathrm{~mm})$

— Line of equality

--- Lydon and Balendran (1986)

-..- BS8100 Part 2

--- Popovics (1975)

..... Best-fit line for experimental data in this study $\left(E_{c 150}=0.44 E_{d, T R 100}^{1.15}, R^{2}=0.90\right)$

(b)

○ $\quad$ Mix $1(100 \times 200 \mathrm{~mm})$

ㅁ $\operatorname{Mix} 2(100 \times 200 \mathrm{~mm})$

$\triangle \quad$ Mix $3(100 \times 200 \mathrm{~mm})$

— Line of equality

--- Lydon and Balendran (1986)

-..- BS8100 Part 2

- - Popovics (1975)

..... Best-fit line for experimental data in this study $\left(E_{c 100}=0.40 E_{d, L R 100}^{1.18}, R^{2}=0.88\right)$

(d)

Figure 8: Continued. 

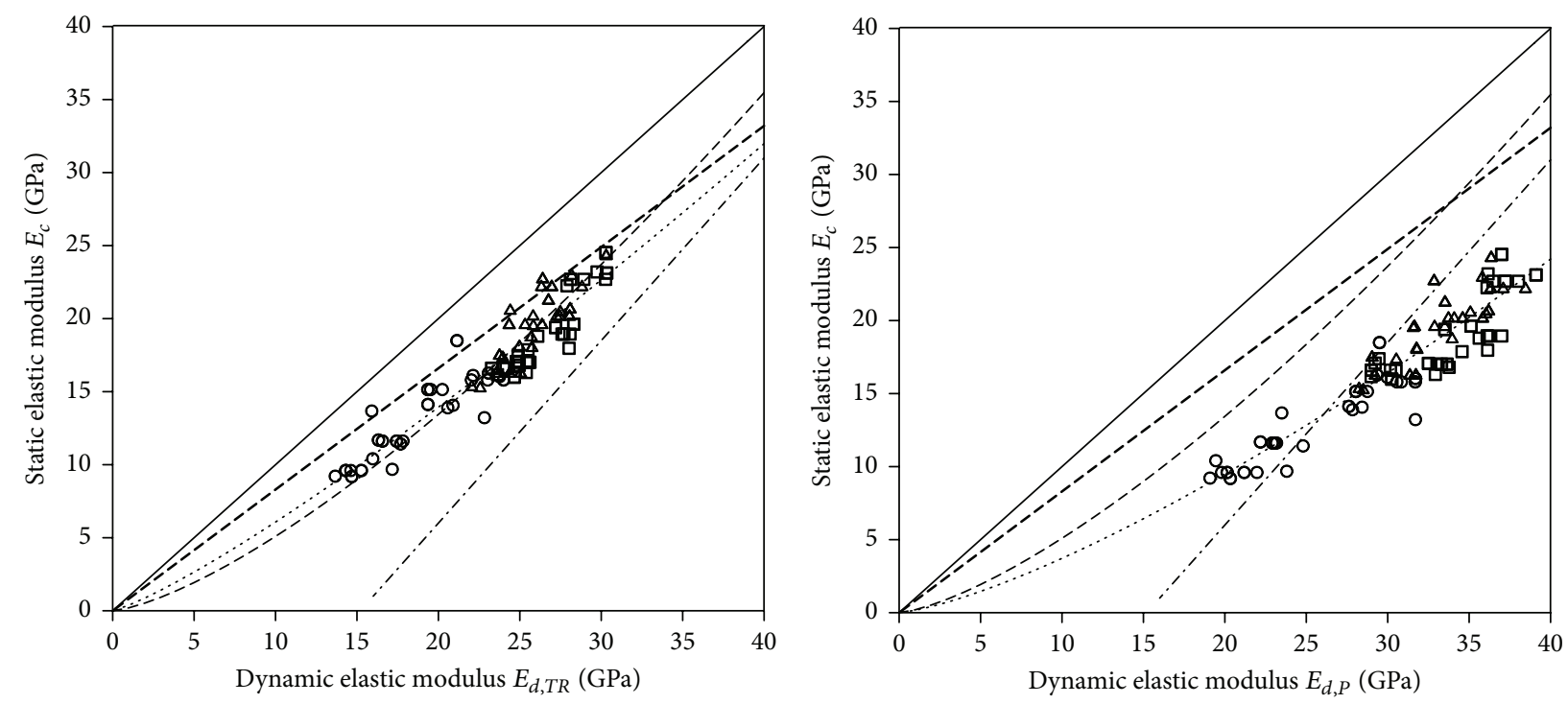

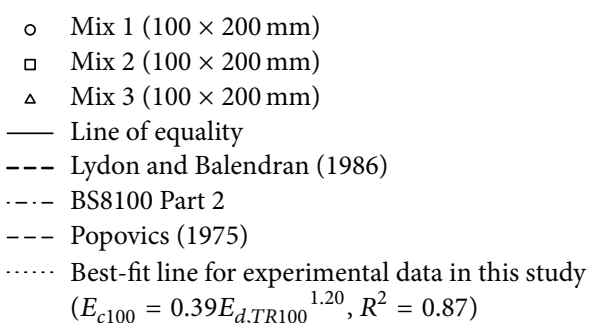

(e)

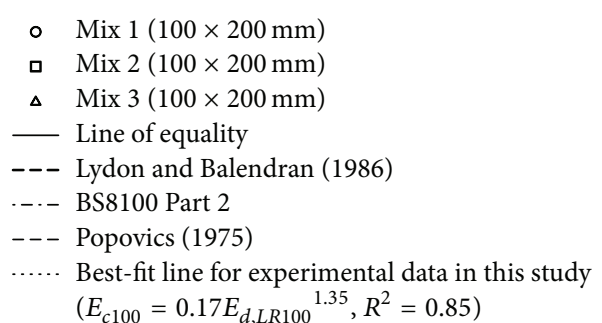

(f)

Figure 8: Comparison of static and resonance elastic moduli of concrete: (a) $E_{d, L R 150}$ versus $E_{c, 150}$, (b) $E_{d, T R 150}$ versus $E_{c, 150}$, (c) $E_{d, P 150}$ versus $E_{c, 150},(\mathrm{~d}) E_{d, L R 100}$ versus $E_{c, 100}$, (e) $E_{d, T R 100}$ versus $E_{c, 100}$, and (f) $E_{d, P 100}$ versus $E_{c, 100}$.

TABLE 4: Mean absolute error (MAE) of expressions relating static and dynamic elastic modulus measured using 100 by $200 \mathrm{~mm}$ and 150 by $300 \mathrm{~mm}$ cylinders.

\begin{tabular}{|c|c|c|c|c|c|c|}
\hline \multirow{3}{*}{ Equation to convert $E_{d}$ to $E_{c}$} & \multicolumn{6}{|c|}{$\operatorname{MAE}(\mathrm{GPa})$} \\
\hline & \multicolumn{3}{|c|}{150 by $300 \mathrm{~mm}$ cylinder } & \multicolumn{3}{|c|}{100 by $200 \mathrm{~mm}$ cylinder } \\
\hline & $E_{d, L T}$ & $E_{d, R T}$ & $E_{d, P}$ & $E_{d, L T}$ & $E_{d, R T}$ & $E_{d, P}$ \\
\hline Equation (4) & 3.02 & 2.82 & 7.54 & 2.83 & 2.54 & 8.46 \\
\hline Equation (5) & 5.59 & 5.91 & 2.77 & 6.07 & 6.49 & 3.35 \\
\hline Equation (6) & 1.25 & 1.11 & 6.58 & 1.13 & 1.07 & 7.80 \\
\hline Best-fit line & 0.90 & 0.95 & 1.26 & 1.09 & 1.10 & 1.17 \\
\hline
\end{tabular}

It is observed that there is only slight difference in the relationship between $E_{c}$ and $E_{d}$ obtained from 100 by $200 \mathrm{~mm}$ and 150 by $300 \mathrm{~mm}$ cylinders. In this study, approximated equations that relate $E_{c}$ and $E_{d}\left(E_{d, P}, E_{d, L R}\right.$, or $\left.E_{d, T R}\right)$ from 100 by $200 \mathrm{~mm}$ and 150 by $300 \mathrm{~mm}$ cylinders were established by nonlinear regression analyses and shown in Figures 8(a)-8(f). The MAEs of the two best-fit curves are less than $0.1 \mathrm{MPa}$ in the dynamic elastic modulus range of $10 \mathrm{GPa}$ to $25 \mathrm{GPa}$. Furthermore, there is no significant difference in $R^{2}$ values of the two best-fit curves (see Figure 8). However, for both data sets from different cylinders, the three dynamic moduli $\left(E_{d, L R}\right.$, $E_{d, T R}$, and $\left.E_{d, P}\right)$ obtained from resonance tests and UPV method are greater than the static elastic modulus $E_{c}$, with different static-to-dynamic elastic modulus ratio. $E_{c} / E_{d, P}$ ratio, with an average of 0.56 and COV of $9.2 \%$, is too far away from the line of equality as well as from the three wellknown equations relating static and dynamic elastic modulus. Therefore, the use of $E_{d, P}$ appears to be inappropriate to estimate static elastic modulus, which is consistent with observations from other researchers [7, 10]. In contrast, $E_{c} / E_{d, L R}$ (or $E_{c} / E_{d, T R}$ ) ratio was closer to the line of equality than $E_{c} / E_{d, p}$, with an average of 0.72 and COV of $7.15 \%$. The equation proposed by Popovics [13] (see (6)) shows very good agreement with the experimental results regardless of cylinder size in this study (see Table 4). In addition, prior researcher [7] observed that the Popovics equation (see (6)) can be extended to high strength concrete up to $60 \mathrm{MPa}$ without regard to cylinder size. However, it should be mentioned 
that additional experimental data should be accumulated to better understand the size effect on the relationship between static and dynamic elastic moduli of high strength concrete (>60 MPa) due to scarcity of experimental studies in such a high strength range.

\section{Conclusions}

A series of experimental studies was conducted to explore the effect of cylinder size (100 by $200 \mathrm{~mm}$ and 150 by $300 \mathrm{~mm}$ cylinders) on the relationship between static elastic modulus and compressive strength and static and dynamic elastic moduli of concrete. Conclusions based on experiments in this study and database from the literature are drawn as follows:

(1) Experimental results in this study show that the COVs of test results from 100 by $200 \mathrm{~mm}$ cylinders are about $10 \%$ higher than those from 150 by $300 \mathrm{~mm}$ cylinders: however, the differences are statistically insignificant. The average COVs of static and dynamic elastic moduli using the UPV and longitudinal and transverse resonance frequency tests from 100 by $200 \mathrm{~mm}$ cylinders are $6.32 \%, 1.40 \%, 1.62 \%$, and $1.17 \%$, respectively, while those values from 150 by $300 \mathrm{~mm}$ cylinders are $5.83 \%, 1.23 \%, 1.62 \%$, and $1.17 \%$, respectively. For compressive strength, the average COVs from the 100 by $200 \mathrm{~mm}$ and 150 by $300 \mathrm{~mm}$ cylinders are $4.41 \%$ and $3.65 \%$, respectively.

(2) According to the findings from similarity tests of bestfit curves and comparison of $R^{2}$ based on regression analyses, it has been demonstrated that the effect of cylinder size (100 by $200 \mathrm{~mm}$ and 150 by $300 \mathrm{~mm}$ cylinders) is insignificant on compressive strength and static elastic modulus and the relationship between the two parameters for normal strength concrete up to $30 \mathrm{MPa}$. However, in the higher strength range greater than $30 \mathrm{MPa}$, there is contradiction in the relationship between $F_{c 150}$ and $F_{c 100}$ based on experimental test in this study and database reported by different researchers. Therefore, it is difficult to establish a simple equation that relates $F_{c 100}$ and $F_{c 150}$, and $E_{c 100}$ and $E_{c 150}$ because of limited experimental and theoretical studies.

(3) The three code equations tend to overestimate static modulus of concrete compared to those from direct measurement according to ASTM C469, with MAE in a range of $4.4 \mathrm{GPa}$ to $12 \mathrm{GPa}$. In contrast, the Noguchi equation predicts experimental results with far more improved accuracy (i.e., MAE less than $2 \mathrm{GPa}$ ) by addressing correction factors for the effects of aggregates and mineral admixtures (i.e., $k_{1}=k_{2}=$ $0.95)$.

(4) There is only a slight difference in the relationship between static and resonance moduli from 100 by $200 \mathrm{~mm}$ and 150 by $300 \mathrm{~mm}$ cylinders for normal strength concrete. Test results from this study and the literature show that the empirical equation suggested by Popovics [13] ((6) in this study) is effective for predicting static elastic moduli from resonance moduli of concrete with compressive strength up to $60 \mathrm{MPa}$ regardless of the cylinder size, with MAE of less than $1.5 \mathrm{GPa}$.

(5) However, the velocity moduli are excessively greater than static elastic modulus. The empirical equations (see (4), (5), and (6)) produce considerable errors (with MAE in a range of $2.77 \mathrm{GPa}$ to $8.46 \mathrm{GPa}$ ) between measured and predicted elastic moduli. Therefore, the use of velocity moduli appears to be inappropriate to estimate static elastic modulus.

\section{Conflict of Interests}

The authors declare that there is no conflict of interests regarding the publication of this paper.

\section{Acknowledgment}

This research was supported by the Basic Science Research Program through the National Research Foundation of Korea (NRF) funded by the Ministry of Science, ICT \& Future Planning (no. 2015R1A5A1037548).

\section{References}

[1] ACI Committee 318, Building Code Requirements for Structural Concrete (ACI 318-11) and Commentary, American Concrete Institute, Farmington Hills, Mich, USA, 2014.

[2] IBC Council, International Building Code (IBC 2012), 2014.

[3] N. Gucunski, A. Imani, F. Romero et al., "Nondestructive testig to identify concrete bridge deck deterioration," SHRP 2 Report S2-R06A-RR-1, 2013.

[4] ACI Committee 469, Standard Test Method for Static Modulus of Elasticity and Poisson's Ratio of Concrete in Compression, American Concrete Institute, Farmington Hills, Mich, USA, 2014.

[5] A. Pauw, "Static modulus of elasticity of concrete as affected by density," ACI Journal Proceedings, vol. 57, no. 12, pp. 679-687, 1960.

[6] ACI Committee 363, "State-of-the-art report on high-strength concrete," ACI Journal, Proceedings, vol. 81, no. 4, pp. 364-411, 1984.

[7] J. S. Popovics, "A study of static and dynamic modulus of elasticity of concrete," ACI-CRC Final Report, 2008.

[8] T. Noguchi, F. Tomosawa, K. M. Nemati, B. M. Chiaia, and A. R. Fantilli, "A practical equation for elastic modulus of concrete," ACI Structural Journal, vol. 106, no. 5, pp. 690-696, 2009.

[9] R. E. Philleo, "Comparison of results of three methods for determining Young's modulus of elasticity of concrete," International Concrete Abstracts Portal, vol. 51, no. 1, pp. 461-469, 1955.

[10] A. M. Neville, Properties of Concrete, John Wiley \& Sons, New York, NY, USA, 4th edition, 1997.

[11] F. D. Lydon and R. V. Balendran, "Some observations on elastic properties of plain concrete," Cement and Concrete Research, vol. 16, no. 3, pp. 314-324, 1986.

[12] B. S. Institute, "Structural use of concrete-part 2: code of practice for special circumstance," BS 8110-2:1995, BSI, London, UK, 1995. 
[13] S. Popovics, "Verification of relationships between mechanical properties of concrete-like materials," Materials and Structures, vol. 8, no. 3, pp. 183-191, 1975.

[14] ASTM C191, Standard Practice for Making and Curing Concrete Test Specimens in the Laboratory, ASTM, 2014.

[15] ASTM, "Standard practice for making and curing concrete test specimen in the field," ASTM C31, ASTM International, 2012.

[16] ASTM International, "Standard test method for fundamental transverse, longitudinal, and torsional resonant frequencies of concrete specimens," ASTM C215, ASTM International, West Conshohocken, Pa, USA, 2002.

[17] P.-C. Aitcin and P. K. Mehta, "Effect of coarse-aggregate characteristics on mechanical properties of high-strength concrete," ACI Materials Journal, vol. 87, no. 2, pp. 103-107, 1990.

[18] P.-C. Aitcin, B. Miao, W. D. Cook, and D. Mitchell, "Effects of size and curing on cylinder compressive strength of normal and high-strength concretes," ACI Materials Journal, vol. 91, pp. 349-354, 1994.

[19] P. M. Carrasquillo and R. L. Carrasquillo, "Evaluation of the use of current concrete practice in the production of high strength concrete," ACI Materials Journal, vol. 85, no. 1, pp. 49-54, 1988.

[20] R. L. Carrasquillo, A. H. Nilson, and F. O. Slate, "Properties of high strength concrete subject to short-term loads," Journal of the American Concrete Institute, vol. 78, no. 3, pp. 171-178, 1981.

[21] J. E. Cook, "10000 psi concrete," Concrete International, vol. 11, pp. 67-75, 1989.

[22] A. S. Malaikah, "A proposed relationship for the modulus of elasticity of high strength concrete using local materials in Riyadh," Journal of King Saud University - Engineering Sciences, vol. 17, pp. 1-11, 2005.

[23] A. Mokhtarzadeh and C. French, "Mechanical properties of high-strength concrete with consideration for precast applications," ACI Materials Journal, vol. 97, no. 2, pp. 136-147, 2000.

[24] D. Vandergrift Jr. and A. K. Schindler, "The effect of test cylinder size on the compressive strength of sulfur capped concrete specimens," Tech. Rep. IR-06-01, Highway Research Center and Department of Civil Engineering at Auburn University, Auburn, Ala, USA, 2006.

[25] ASTM International, "Standard test method for compressive strength of cylindrical concrete specimens," ASTM C39, ASTM International, West Conshohocken, Pa, USA, 2014.

[26] ASTM, "Standard test method for pulse velocity through concrete," ASTM C597, ASTM International, 1997.

[27] N. J. Carino, W. F. Guthrie, E. S. Lagergren, and G. M. Mullings, "Effects of testing variables on the strength of high-strength (90MPa) concrete cylinders," in High-Performance Concrete, V. M. Malhotra, Ed., SP-149, pp. 589-632, American Concrete Institute, Farmington Hills, Mich, USA, 1994.

[28] ACI, "Guide for evaluation of strength test results of concrete (ACI 214R-11)," ASTM C214, American Concrete Institute, Farmington Hills, Mich, USA, 2011.

[29] ACI Committee 228, "Nondestructive test methods for evaluation of concrete in structures," Report ACI 228.2R-98, American Concrete Institute, Farmington Hills, Mich, USA, 1998.

[30] S. A. Issa, M. S. Islam, M. A. Issa, A. A. Yousif, and M. A. Issa, "Specimen and aggregate size effect on concrete compressive strength," Cement Concrete and Aggregates, vol. 22, no. 2, pp. 103-115, 2000. 

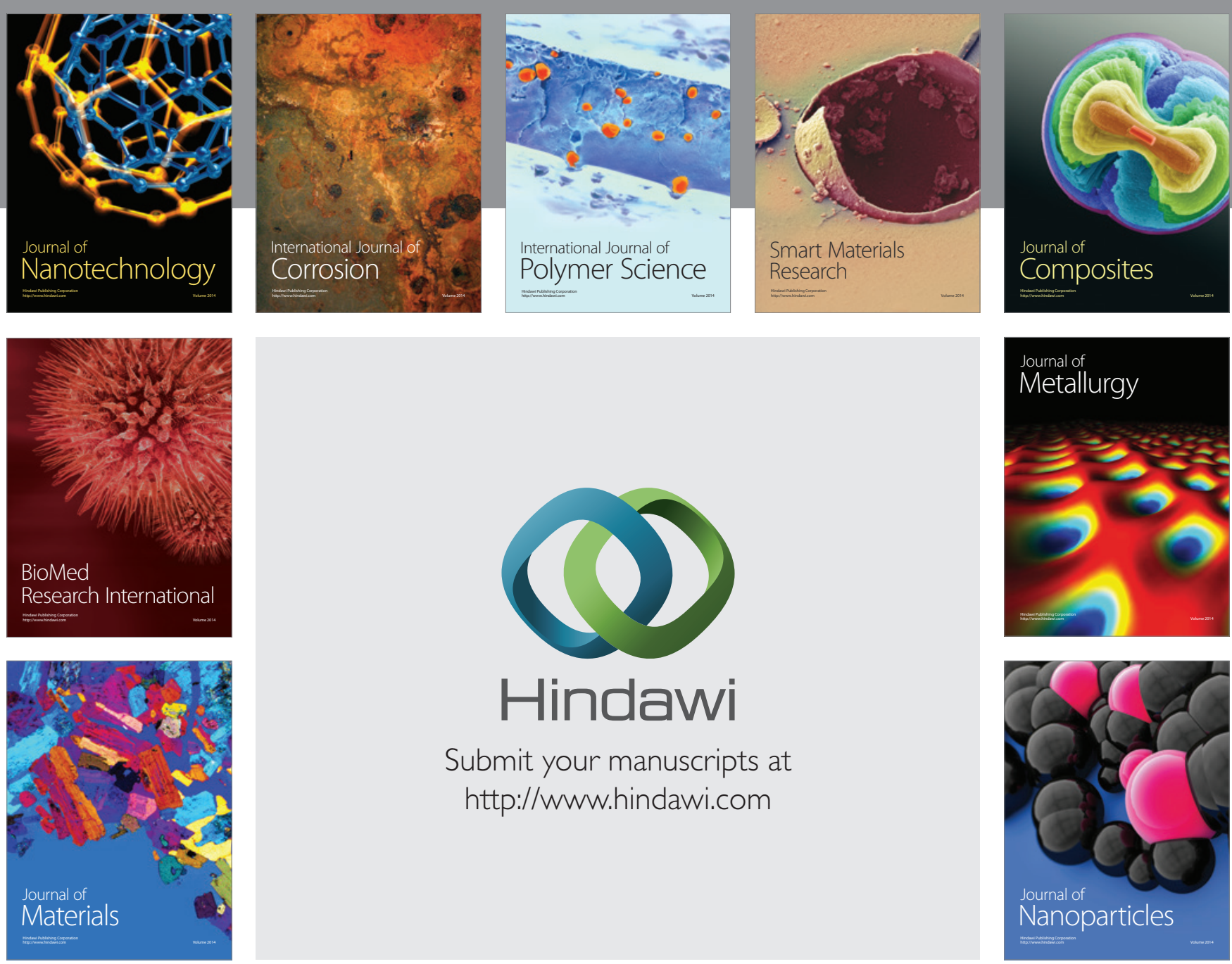

Submit your manuscripts at http://www.hindawi.com
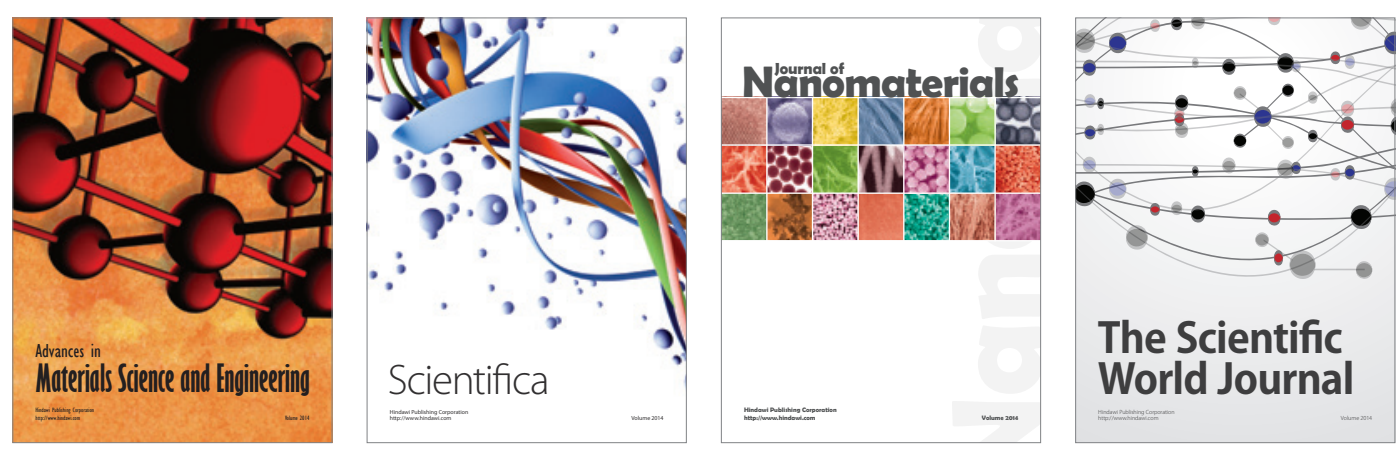

\section{The Scientific World Journal}
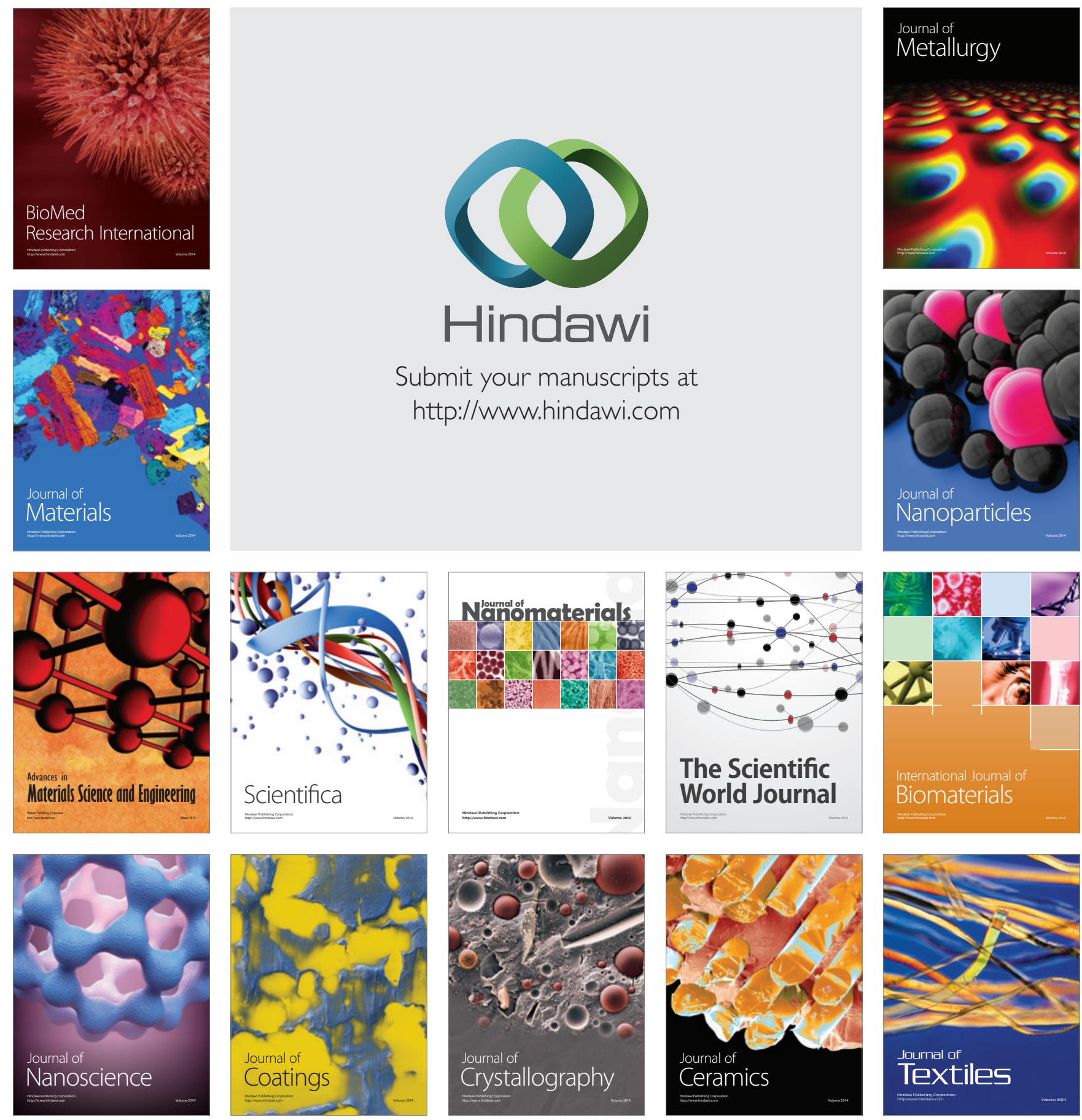